8 Shah SM, Spalton DJ, Allen RJ, Smith SE. A comparison of the laser cell meter and fluorophotometry in assessment of the blood-aqueous barrier. Invest Ophthalmol Vis Sci 1993; 34: 3124-30.

Relation between blood glucose control over 3 months and colour discrimination in insulin dependent diabetic patients without retinopathy

EDITOR,-Visual pathway function may be abnormal in patients with insulin dependent diabetes (IDDM) with angiographically normal retinas. ${ }^{1}$ This could be a result of reversible changes in visual pathway function, dependent upon blood glucose control. When blood glucose was fixed for several hours at predetermined levels (2.5-14 $\mathrm{mmol} / \mathrm{l}$ ) using a hyperinsulinaemic glucose clamp, no difference in colour discrimination in non-retinopathic IDDM patients was found. ${ }^{2}$ We have therefore conducted a preliminary study to investigate the relation between changes in intermediate term (over 3 months) blood glucose control and colour discrimination.

Eleven clinically non-complicated IDDM patients of median age 35 (interquartile range 27-37) years and with diabetes duration 8 (6-16) years, without evidence of retinopathy on single $\left(45^{\circ}\right)$ field fundus photography participated in the study. Most (8/11) had also had fluorescein angiography (which was normal) within 1 year. None was receiving medication other than insulin. They were assessed at 0 and 3 months, with measurement of glycated haemoglobin $\left(\mathrm{HbA}_{1}\right.$, reference range 5.5-8.2\%) (Corning Medical, Corning, NY, USA). Colour discrimination was assessed by means of the FarnsworthMunsell 100-Hue test as described previously. ${ }^{1}$ Neither patient nor examiner was aware of the patient's $\mathrm{HbA}_{1}$ at colour vision assessment.

Patients were divided into two groups on the basis of 3 month $\mathrm{HbA}_{1}$ results: in the first group $(n=6)$ diabetes control had improved over 3 months $\left(\mathrm{HbA}_{1} 11.5 \%\right.$ (9.8-12.6\%) to $9.4 \%(7.6-11.0 \%), p<0.05)$, in the second group $(n=5)$ diabetes control had deteriorated over 3 months $\left(\mathrm{HbA}_{1} \mathbf{9} \cdot \mathbf{8} \%\right.$ $(8 \cdot 9-10.4 \%)$ to $11.2 \% \quad(10.4-12.9 \%)$, $\mathrm{p}<0.05)$. Baseline age, diabetes duration, and 100 -Hue error score were similar in the two groups.

Comparisons between groups were by Mann-Whitney U test and within group comparisons at 0 and 3 months by Wilcoxon's signed rank test. The 100-Hue error scores were normalised by square root transformation ${ }^{3}$ and were compared by paired $t$ test

In the group in which glycaemic control improved, colour discrimination improved significantly over 3 months: mean (SD) square root 100 -Hue error score $7.5(2.7)$ to $5.9(2.2)$ at 3 months, $p<0.05$. By contrast, when glycaemic control worsened, colour discrimination worsened $6.6(4.3)$ to $8.3(3.9)$ at 3 months, $p<0 \cdot 05$. No patient had a specific axis of colour discrimination loss.

These preliminary data support an association between colour discrimination and intermediate term glycaemic control and confirm prospectively the correlation between glycated haemoglobin and colour discrimination observed in the cross sectional study of Muntoni et al. ${ }^{4}$ That colour discrimination changes reflect changes in visual pathway function rather than alterations in concentration or cerebral function is supported by the observation that other tests of visual pathway function have improved with better glycaemic control. 56

The mechanism of the relation between glycaemic control and changes in visual function is unclear. It may be that excess or deficiency of some product of intermediary metabolism affects cone pathway function, or that the function of some key visual pathway enzyme is affected by abnormal glycosylation. It may be that hyperglycaemia induced alterations in retinal blood flow affect delivery of oxygen and nutrients to cells of the visual pathways. These issues remain unresolved.

KEVIN J HARDY
Department of Diabetes,
Royal Infirmary of Edinburgh,
Lauriston Place,
Edinburgh EH3 9YW
JOHN H B SCARPELLO
Department of Endocrinology and Diabetes,
North Staffordshire Royal Infirmary
DAVID H FOSTER
Department of Communication and Neuroscience,
Keele University

1 Hardy KJ, Lipton J, Scase MO, Foster DH, Scarpello JHB. Detection of colour vision abnormalities in uncomplicated type 1 diabetic patients with angiographically normal retinas. patients with angiographically no
$B r f$ Ophthalmol 1992; 76: 461-4.

2 Hardy KJ, Scase MO, Foster DH, Scarpello JHB Effect of short term changes in blood glucose on visual pathway function in insulin dependent diabetes. Br J Ophthalmol 1995; 79: 38-41.

3 Kinnear PR. Proposals for scoring and assessing the 100-Hue test. Vision Res 1970; 10: 423-33.

4 Muntoni S, Serra A, Mascia C, Songini M. Dyschromatopsia in diabetes mellitus and its relation to metabolic control. Diabetes Care relation to metabo

5 Lauritzen T, Frost-Larsen K, Larsen HW, Deckert T, and the Steno Study Group. Effect of one year of near-normal blood glucose levels on retinopathy in insulin-dependent diabetics. Lancet 1983; i: 200-4.

6 Algan M, Ziegler O, Eck Ph, Drouin P. Influence of glycaemic control on visual evoked potentials in diabetic patients. Invest Ophthalmol Vis $S c i$ 1991; 32: 1142.

\section{Mapstone's hypothesis confirmed}

EDITOR,-In 1979, Mapstone ${ }^{1}$ suggested that angle closure could begin with iridocorneal apposition to the angle wall at the level of Schwalbe's line before the development of iridotrabecular contact. He presented clinical evidence obtained at the slit-lamp to show that, since the peripheral curvatures of cornea and iris are different, there is a finite distance between the trabecular meshwork and iris root anterior to the iris insertion. In this situation, intraocular pressure (IOP) would remain normal until the aqueous humour present in the space between the iris root and trabecular meshwork had exited the eye. Increasing aqueous humour volume in the posterior chamber and increasing iris apposition to the meshwork as the aqueous between the meshwork and iris root diminished, would then lead to angle closure glaucoma with elevated IOP.

Using high frequency, high resolution, anterior segment ultrasound biomicroscopy (UBM) ${ }^{2}$ we have been able to show that the iris configuration hypothesised by Mapstone does occur. An 82-year-old man was referred with a diagnosis of closed angles and normal IOP. Gonioscopy revealed slit to grade I angles in bright light which, when the room was darkened and a small, square slit beam used to illuminate the angle, became appositionally closed.

UBM imaging revealed iridolenticular apposition and a convex iris configuration diagnostic of pupillary block (Fig 1). The ciliary body $\left({ }^{\star}\right)$ was positioned somewhat

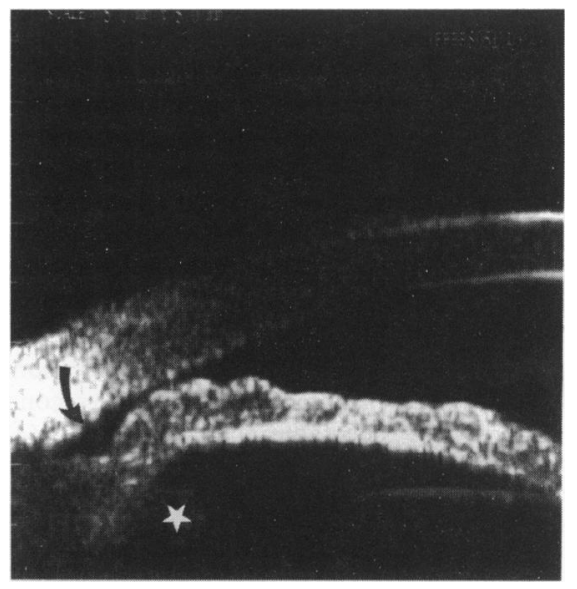

Figure 1 Appositional angle closure (see text for details).

anteriorly, suggesting a component of plateau iris. ${ }^{45} \mathrm{~A}$ triangular space was present at the angle recess (arrow), which narrowed to the point at which the iris was apposed to the external wall of the angle.

Mapstone ${ }^{1}$ had suggested that closure of the angle recess and obliteration of the remaining space would occur after intraocular pressure rose sufficiently so as to push the iris against the trabecular meshwork. The image depicted suggests the possibility of an alternative sequence of events in the initiation of angle closure glaucoma. It is possible that, once iridocorneal apposition is of sufficient duration (for example, prolonged exposure in a darkened room), aqueous present within the angle recess continues to exit through the trabecular meshwork, but cannot be replaced by aqueous from the anterior chamber because of the apposition. As a result, the iris moves naturally to the trabecular meshwork as the volume of aqueous decreases, and when this apposition is increased, then intraocular pressure rises.

\section{ROBERT RITCH ZEEV STEGMAN JEFFREY M LIEBMANN Department of Ophthalmology, The New York Eye and Ear Infirmary, 310 East 14th Street, New York, NY 10003, USA}

1 Mapstone R. One gonioscopic fallacy. $\mathrm{Br} f$ Ophthalmol 1979; 63: 221-4.

2 Pavlin CJ, Sherar MD, Foster FS. Subsurface ultrasound microscopic imaging of the intact ultrasound microscopic imaging of
eye. Ophthalmology 1990; 97: 244-50.

3 Pavlin CJ, Harasiewicz K, Sherar MD, Foster FS. Clinical use of ultrasound biomicroscopy. Ophthalmology 1991; 98: 287-95.

4 Ritch R. Plateau iris is caused by abnormally positioned ciliary processes. I Glaucoma 1992; 1:23-6.

5 Pavlin CJ, Ritch R, Foster FS. Ultrasound biomicroscopy in plateau iris syndrome. $A m \mathcal{F}$ Ophthalmol 1992; 113: 390-5.

\section{NOTICES}

\section{British College of Optometrists}

The centenary conference of the British College of Optometrists will be held at Churchill College, Cambridge on 5-8 April 1995. Further details: BCO Conference Secretariat, Conference Contact, 42 Devonshire Road, Cambridge CB1 2BL. (Tel: 01223 323437; Fax: 01223 460396.) 